\title{
Contrast-Enhanced Ultrasound of lymph nodes: towards better imaging
}

\author{
Adrian Săftoiu \\ Research Center of Gastroenterology and Hepatology Craiova, University of Medicine and Pharmacy Craiova, \\ Romania
}

We read with great interest the article by Poanta $L$ et al entitled "The place of CEUS in distinguishing benign from malignant cervical lymph nodes: a prospective study." published in the current number of Medical U1trasonography [1]. The article describes the role of contrast-enhanced ultrasound (CEUS) as compared to grayscale and color Doppler ultrasound for the differential diagnosis of benign versus malignant superficial cervical lymph nodes. The study was prospective and included 61 patients with cervical lymphadenopathy, with the final diagnosis obtained through biopsy or after surgery. The authors compared various parameters obtained by grayscale ultrasound, Doppler parameters (vessel location, vascular pattern, pedicullum number, resistivity, and pulsatility index) and CEUS parameters (enhancement pattern, derived peak intensity, regional blood volume (RBV), time to peak and area under the curve). Furthermore, they tried to incorporate CEUS in the algorithm conventionally used for the differential diagnosis of benign and malignant lymph nodes.

An imaging method with a high sensitivity and specificity for the differential diagnosis would certainly be needed in order to choose the most probable lymph node that should be subsequently targeted by ultrasound guided fine needle aspiration biopsy. Nevertheless, the task is not simple as various authors tried to compare various state-of-the-art technologies like ultrasound and mag-

Received Accepted

Med Ultrason

2014, Vol. 16, No 1, 5-6

Corresponding author: Adrian Saftoiu

Research Center of Gastroenterology and Hepatology

University of Medicine and Pharmacy

1Mai Bvd, no 60, 200355 Craiova, Dolj

Romania

Phone/Fax: +40251310.287

E-mail: adrian.saftoiu@umfcv.ro netic resonance imaging [2]. Ultrasound is particularly useful as a cheap high-resolution method, available at the point-of-care, including in low-income resource settings. However, gray-scale ultrasound has a low accuracy for the differential diagnosis of benign and malignant lymph nodes [3]. Thus, using the transverse-to-longitudinal diameter ratio in combination with texture and margin analysis, the correct diagnosis can be made in only approximately $80 \%$ of the lymph nodes. This has been also shown in the initial studies that used endoscopic ultrasound as a high resolution technique used to image mediastinal or abdominal lymph nodes [4]. None of the gray-scale derived features (size greater than $1 \mathrm{~cm}$, hypoechoic, distinct margins, and round shape) are considered independent predictors of malignancy of the lymph nodes. Other proposed features like irregular echogenic foci representing coagulation necrosis, are still underrecognized although it could have a high positive predictive value for malignancy of approximately $90 \%$ [5].

Contrast-enhanced color or power Doppler has been used consistently for the differential diagnosis, yielding better results as compared to gray-scale analysis of lymph nodes [6]. Other authors found that contrastenhancement is not needed in comparison with native colour and power Doppler [7]. Excellent results have been also found in the study of Poanta L et al [1], for the receiver operator curve (ROC) analysis for both the resistivity index (RI) and pulsatility index (PI), used for the differential diagnosis of benign and malignant lymph nodes. Low-mechanical index CEUS has been proposed as a better method of evaluation for microvascular changes, including necrosis or tumor angiogenesis [8]. Thus, the EFSUMB Guidelines and Recommendations on the Clinical Practice of Contrast Enhanced Ultrasound (CEUS): Update 2011 on non-hepatic applications [9] recommended the use of CEUS for the differential diagnosis of benign and malignant superficial lymph nodes in 
special clinical settings, without being useful for routine discrimination. Also, CEUS with subcutaneous injection of contrast for identification of the sentinel lymph node is considered a field of ongoing research, not ready for clinical practice. Nonetheless, although not perfect, CEUS yielded good results in a few published studies, better than conventional ultrasonography, with an accuracy of approximately $80 \%$. This is especially true for quantitative analysis of CEUS time-intensity curves, with good values reported in the current study, especially for the CEUS enhancement pattern and regional blood flow (RBV) [1]. The authors also made efforts in finding the right place for CEUS in the current algorithms used for the ultrasound evaluation and differentiation of benign and malignant lymph nodes. The technique should be used in the uncertain cases where the information obtained from gray-scale and Doppler studies is not enough for a correct diagnosis, because the added value of CEUS yields a high accuracy of the differential diagnosis. This should not preclude the usage of ultrasound-guided FNA biopsy, especially if a positive result would change consistently the clinical management of the patient.

In conclusion, the usage of CEUS for the differential diagnosis of benign and malignant superficial lymph nodes is still controversial, while the data brought by the current article might solve some missing pieces of the puzzle. Other techniques like elastography might also add to the complexity of the problem [10], although complementary informations are always desirable to increase the accuracy of differential diagnosis in between benign and malignant lymph nodes [11,12]. Last, but not least, US-guided FNA biopsy should be left in place as the method of choice for confirmation of the diagnosis, while the role of imaging should not be over-emphasized.

\section{References}

1. Poanta L, Serban O, Pascu I, Pop S, Cosgarea M, Fodor D. The place of CEUS in distinguishing benign from malignant cervical lymph nodes: a prospective study. Med Ultrason 2014; 16: pag. 7-14.
2. Wendl CM, Müller S, Meier J et al. High resolution contrast-enhanced ultrasound and 3-tesla dynamic contrastenhanced magnetic resonance imaging for the preoperative characterization of cervical lymph nodes: First results. Clin Hemorheol Microcirc 2012; 52: 153-166.

3. Moritz JD, Ludwig A, Oestmann JW. Contrast-enhanced color Doppler sonography for evaluation of enlarged cervical lymph nodes in head and neck tumors. AJR Am J Roentgenol 2000; 174: 1279-1284.

4. Bhutani MS, Hawes RH, Hoffman BJ. A comparison of the accuracy of echo features during endoscopic ultrasound (EUS) and EUS-guided fine-needle aspiration for diagnosis of malignant lymph node invasion. Gastrointest Endosc 1997; 45: 474-479.

5. Bhutani MS, Saftoiu A, Chaya C, et al. Irregular echogenic foci representing coagulation necrosis: a useful but perhaps under-recognized EUS echo feature of malignant lymph node invasion. J Gastrointestin Liver Dis 2009; 18: 181184.

6. Yang WT, Metreweli C, Lam PK, Chang J. Benign and malignant breast masses and axillary nodes: evaluation with echo-enhanced color power Doppler US. Radiology 2001; 220: 795-802.

7. Schulte-Altedorneburg G, Demharter J, Linné R, Droste DW, Bohndorf K, Bücklein W. Does ultrasound contrast agent improve the diagnostic value of colour and power Doppler sonography in superficial lymph node enlargement? Eur J Radiol 2003; 48: 252-257.

8. Yu M, Liu Q, Song HP, et al. Clinical application of contrast-enhanced ultrasonography in diagnosis of superficial lymphadenopathy. J Ultrasound Med 2010; 29: 735-740.

9. Piscaglia F, Nolsøe C, Dietrich CF, et al. The EFSUMB Guidelines and Recommendations on the Clinical Practice of Contrast Enhanced Ultrasound (CEUS): update 2011 on non-hepatic applications. Ultraschall Med 2012; 33: 33-59.

10. Dudea SM, Botar-Jid C, Dumitriu D, Vasilescu D, Manole $\mathrm{S}$, Lenghel ML. Differentiating benign from malignant superficial lymph nodes with sonoelastography. Med Ultrason 2013; 15: 132-139.

11. Cui XW, Jenssen C, Saftoiu A, Ignee A, Dietrich CF. New ultrasound techniques for lymph node evaluation. World J Gastroenterol 2013; 19: 4850-4860.

12. Ying M, Bhatia KS, Lee YP, Yuen HY, Ahuja AT. Review of ultrasonography of malignant neck nodes: greyscale, Doppler, contrast enhancement and elastography. Cancer Imaging 2014; 13: 658-669. 